九州大学学術情報リポジトリ

Kyushu University Institutional Repository

\title{
Verhütung Der Viruserkrankung Durch Eisenverbindungen
}

\section{Yamafuji, Kazuo}

Agrikulturchemischen Institut der Kyushu-Universität

Goya, Tsutomu

https://doi.org/10.5109/22637

出版情報: 九州大学大学院農学研究院紀要. 9 (4), pp. 325-331，1950-11. Kyushu University バージョン：

権利関係 : 
Journal of the Faculty of Agriculture, Kyūshū LIniversity, Vol. 9, No. 4 November 30,1950

\title{
VERHÜTUNG DER VIRUSERKRANKUNG DURCH EISENVERBINDUNGEN
}

\author{
Kazuo Yamafuj und Tsutomu GoYa
}

Wirkt das Wasserstoffperoxyd auf das Nucleoprotein in der Zelle, so wird das Eiweissmolekül unter Umständen erst denaturiert und dann polymerisiert. Dies sind die Hauptvorgänge der Virusbildung und bildet die Grundreaktionen für unsere Virustheorie. Die Theorie der Virusentstehung wird als folgendermassen formuliert :

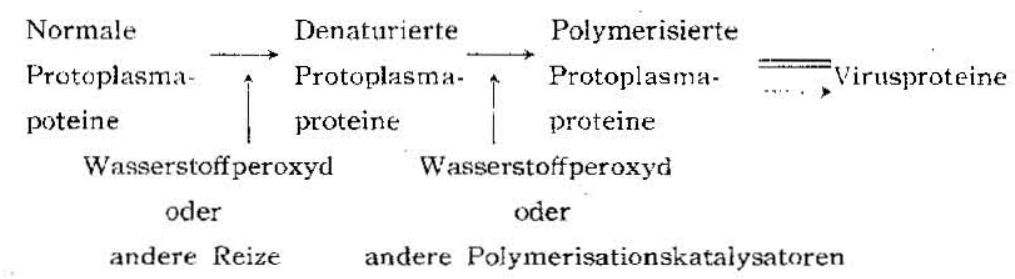

Eiweisskörper, die hauptsächlich bei diesen Vorgängen Denaturierung sowie Polymerisation erleiden, sind die Nucleoproteine im Protoplasma. Katalysator, der in den meisten Fällen derartige Veränderungen der Proteinnatur bewirkt, ist das Hydroperoxyd; aber es scheint möglich $z u$ sein, dass bei komplexen Lebensprozessen andere Mittel entstehen, welche die gleichen Wirkungen ausüben. Die so aggregierten Proteinmoleküle bekommen nicht immer eine Virusnatur: Die Erlangung der Eigentümlichkeiten als Virusmolekül, die Spezifizität oder Figenschaften der entstandenen Virusproteine und ferner die Differenzierung der Virusarten sind von dem Polymerisationsgrad des Protoplasmaeiweisses sowic der Empfindlichkeit des betreffenden Gewebes abhängig. Auf jenen Fall sind diese Erscheinungen grösstenteils von der Stärke der Hydroperoxydwirkung bedingt, und Wasserstoffperoxyd, das in solcher Weise stets bei den Entstehungsvorgängen des Virus 
die wichtigste Rolle spielt, wird nach unserer Atmungstheorie fortwährend durch folgende Reaktion gebildet :

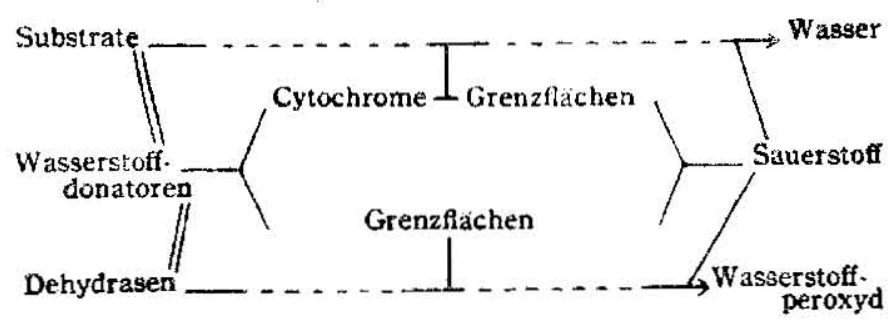

Wenn nämlich die Wasserstoffdonatoren mit den Sauerstoffmolekülen, die durch Grenzflächen allein aktiviert wurden, reagie. ren, so entsteht das Wasserstoffperoxyd. Derartige Sauerstoffaktivierung ist, wie wir schon oft bewiesen hatten, sehr kräftig, und folglich kann solche Hydroperoxydbildung als in allgemeiner biologischer Prozess betrachtet werden. Um die Einwirkung des Wasserstoffperoxyds auf die Protoplasmaproteine möglichst $\mathrm{zu}$ vermeiden, muss man daher entweder die Wirksamkeit der Cytochrome oder die der Katalase in der Zelle erhöhen. Das ist ein theoretischer Weg zur Vorbeugung und Heilung von Viruskrankheiten, aber wir wissen nicht, welcherweise wir die Voraussetzung verwirklichen. Es ist doch deutlich, dass die Viruserkrankung, wie aus den Gleichungen (1) und (2) anzunehmen ist, mit dem Eisenatom in enger Beziehung steht. Hier wird erstens die Möglichkeit gegeben, dass durch Füttcrung mit reinem Katalasepräparat eine Virusentsteheng verhütet werden kann, obwohl es noch unklar ist, ob bei der Katalaseversorgung in der Tat eine Katalaseaktivierung im Protoplasm erfolgt. Die Annahme wurde jedoch bei den Versuchen am Seidenspinner bestätigt (1). Zweitens ist es auch möglich, dass wir durch Versorgung mit anderen Eisenverbindungen ebenfalls eine Virusbildung vorbeugen können. Dies ist die Frage, die wir uns in der vorliegenden Arbeit aufzuklären vornahmen.

$\mathrm{Zu}$ diesem $\mathrm{Z}$ wecke wurde zunächst die Wirkung der Hämin. substanzen auf tierische Viruskrankheit untersucht. Wird die Seidenraupe mit Blutpulver, Hämoglobin oder Hämin gefüttert und dann mit Virus infiziert oder erwärmt, so wird beobachtet, dass diese Substanzen das Auftreten der Virose etwas hemmen. Die hemmende Wirkung solcher Stoffe ist aber bedeutend schwächer 
als die der Katalase. Die Ergebnisse sind nicht unerwartet; denn Hämoglobin ist für die Seidenlarve eine physiologisch fremde Substanz, und ausserdem ruft die Hämoglobinfütterung keine so deutliche Steigerung der Katalasewirksamkeit oder der Atmung des Insektes hervor. Es wurde deshalb auf den Einfluss der Eisensalze auf pflanzliche Virose untersucht. Düngt man die Tabakpflanze mit Ferro-oder Ferrisulfat und impft mit Virusprotein, so wird man finden, dass auch diese Salze auf dic Viruserkrankung hemmend wirken. Dic Wirksamkeit der Salze ist ebenfalls nicht so stark. Obgleich wir also nicht imstande waren, unter Benutzung der Eisenverbindungen die Erkrankung vollkommen $z u$ verbüten, stützen die erhaltenen Befunde das oben angeführte Schema, das vor kurzem von uns für die Neubildung sowie Vermehrung der Virusmoleküle in der lebenden Zelle vorgeschlagen wurde. Das Wasserstoffperoxyd entsteht bekanntlich immer bei der Sauerstoffatmung, selbst wenn die Tätigkeit der Katalase oder des Cytochromsystems ausserordentlich erhöht würde. Das Protoplasmaeiweiss kann sonach niemals der Einwirkung des Wasserstoffperoxyds entgehen, und dies stellt, wie oben erwähnt, den ersten grundlegenden Vorgang der Virusbildung dar.

I.

Eine biologisch wichtige und leicht herstellbare Eisenporphyrinverbindung ist das Hämoglobin. Hämoglobin befindet sich im Blute der Vertebraten, aber es ist schwer, bei höheren Tieren ungezwungen und richtig eine Viruskrankheit entstehen zu lassen. Darum benutzten wir hier Seidenraupe, weil bei ihr der Entstehungsmechanismus des Virus im Körper fast vollständig geklärt worden ist. Das verwandte Hämoglobin wurde in $\mathrm{n} / 20 \mathrm{NaOH}$ gelöst und dann mit $n / 5 \mathrm{HCl}$ vorsichtig neutralisiert, bis eine Fällung anfängt. Die Acidität der erhaltenen Lösung war $\mathrm{pH}$ etwa 9. Das $\mathrm{pH}$ entspricht demjenige des Verdauungssaftes der Seidenlarve. Die Maulbeerblätter wurden mit 1\%iger Hämoglobinlösung benetzt und die benetzten Blätter jeden Tag einmal den Larven gegeben. Nach einer Woche wurden die Larven mit Blättern gefüttert, die mit einer Polyederviruslösung befeuchtet worden waren. Die benutzte Viruslösung wurde dadurch dargestellt, das viruskranke Raupen mit Sand zerrieben und mit Wasser versetzt wurden, warauf die Suspension nach dem Zentrifugieren 
mit einem Bakterienfilter filtriert wurde. In den übrigen Fütterungszeiten wurden unbehandelten Blätter verabreicht.

Tabelle $\mathbf{I}$.

\begin{tabular}{c|c|c|c}
\hline $\begin{array}{c}\text { Gefüttert mit: } \\
\text { Zahl der virusertirankten Raupen } \%\end{array}$ & Virus allein & Virus und Hämoglobin \\
\hline
\end{tabular}

Wie aus den Beziehungen zwischen der Hämoglobinfunktion und dem Insektenleben zu erwarten ist, erfolgt bei der Hämoglobinfütterung nur eine unvollkommene Verhütung gegen Virusansteckung. Da jedoch ein ziemlich günstiges Resultat crhalten werden konnte, wurden die Versuche ferner mit Blutpulver oder Hämin ausgeführt. Zur Bereitung des Blutpulvers wurde Ochsenblut bei $60^{\circ}$ getrocknet und pulverisiert. Als Hämin wurden verschiedene Präparate verwendet. Zuerst benutzten wir Lösungen, die durch Hydrolyse des Blutpulvers mit Säuren oder Alkalien hergestellt wurden. Dic Häminlösungen wurden stets auf $\mathrm{pH} 8$ bis 9 eingestellt.

Tabelle II.

\begin{tabular}{c|cc}
\hline Gefuittert mit: & Virus allein & Virus und Hamin \\
\hline Zahl der viruserkrankten Raupen in $\%$ & 20 & 14 \\
\hline
\end{tabular}

Die Virusvermehrung im Raupenkörper wird auch durch Häminversorgung nicht völlig gehemmt. Hierbei war die Konzentration des Hämins unter $0,1 \%$. Zur Kontrollgruppe wurde anstatt der Häminlösung eine Lösung gegeben, die die entsprechende Menge Salz enthält. Bei dem zugleich angestellten Versuch mit Blutpulver ergab sich, dass die hemmende Wirkung des Blutes selbst sehr schwach ist. Um aufzuklären, ob bei den Hemmungs.

Tabelle III.

\begin{tabular}{|c|c|c|c|c|}
\hline Gefüttert mit: & $\begin{array}{l}\text { Virus } \\
\text { alleir }\end{array}$ & $\begin{array}{l}\text { Virus and } \\
\text { Hämoglobin }\end{array}$ & $\begin{array}{l}\text { Virus und } \\
\text { Blutpulver }\end{array}$ & $\begin{array}{l}\text { Virus und } \\
\text { Hämin }\end{array}$ \\
\hline Relative Katalasenktivitat .................. & 100 & 105 & 103 & 106 \\
\hline Relative Atmungsintensitiit $\ldots \ldots \ldots \ldots \ldots$ & 100 & 94 & 92 & 93 \\
\hline
\end{tabular}


erscheinungen der Virusentstehung auch ein anumaler Stoff we chsel, der von unserer Virustheorie her zu erwarten war, stattfindet, bestimmten wir nun die Katalasewirksamkeit und Atmungsintensität der behandelten Larven.

Bei der Versorgung mit den Eisenpyrrolverbindungen erfolgen also sowohl eine Aktivierung der Katalase also auch eine Erniedrigung der Atmung im Gewebe der Raupen. Diese Verschiebung der Oxydationsprozesse ist diejenige, die für die Vorbeugung gegen Viruskrankheiten günstig ist. Der Verschiebungsgrad war aber zu niedrig, um einen genügend starken vorbeugenden Effekt auszuüben.

Die oben beschriebenen Befunde, die bei der Untersuchung über die Einwirkung des Fisens auf die Vermehrung des Virus gewonnen wurden, gaben uns Anlass, weiterhin die Wirkung des Hämatins auf die Neubildung des Virus zu untersuchen. Wie wir früher festgestellt haben, können wir dann bei der Seidenraupe eine Viruskrankheit ohne Virusinfektion entstehen lassen, wenn wir die Larven unter passenden Bedingungen erwärmen. Deshalb wurden die Larven in der oben angegebenen Weise mit Hämatin gefüttert und nach 3 Tagen 10 Minuten in einem Thermostat von $45^{\circ}$ erwärmt. Hierbei benutzten wir als Hämatin ein Präparat, das von uns aus dem Ochsenblut nach der. Mörnerschen Methode (2) hergestellt wurde, oder dasjenige, das von Merck gekauft wurde und als "Hämin nach Mörner" bezeichnet worden ist. Diese Hämatinpräparate wurden als 0,03 bis $0,05 \%$ ige Lösung gegeben.

Tabelle IV.

\begin{tabular}{c|c|c}
\hline Behandlungsweise : & Erwärmung allein & $\begin{array}{c}\text { Erwärmung und } \\
\text { Hämatinfütterung }\end{array}$ \\
\cline { 2 - 3 } Zahl der viruserkrankten Raupen in $\%$ & 19 & 10 \\
\hline
\end{tabular}

Füttert man die Raupe mit reinem Hämatin, so kann die Neubildung der Virusmoleküle im Raupenkörper viel stärker gehemmt werden, als bei der Fütterung mit unreinen Häminsubstanzen. Um zu prüfen, ob die Hemmung der Virusbildung tatsächlich auf die Verhinderung der Hydroperoxydanhäufung in der Zelle zurückzuführen ist, wurden wie üblich die Oxydationsvorgänge ermittelt. 
Bei der Fütterung mit reinem Hämatin findet wie beim Rohhämin eine geringe Verminderung der Atemgrösse statt. Da dabei aber eine deutlich stärkere Erhöhung der Katalasewirkung bewirkt wird, können hierbei die Nucleoproteine bis zu einem gewissen Grad die Einwirkung des Wasserstoffperoxyds vermeiden, und dadurch wird die Viruserkrankung gehindert.

Tabelle V.

\begin{tabular}{|c|c|c|}
\hline Behandlungsweise: & Erwärmung allein & $\begin{array}{l}\text { Erwärmung und } \\
\text { Hämatinfütterung }\end{array}$ \\
\hline Relative Katalaseaktivität & 100 & 135 \\
\hline Relative Atmungsintensitut & 100 & 97 \\
\hline
\end{tabular}

II.

Um das Prinzip der Vorbeugung gegen die Viruskrankheiten zu verallgemeinertı, wurde ferner die Pflanze als Material verwendet. In diesem Falle scheint es geeigneter $\mathrm{zu}$ sein, an Stelle von Häminproteiden anorganische Eisensalze als Vorbeugungsmittel zu geben. Zur Ermittelung des Erkrankungsgrades wurde erst die Zahl der Einzelherde bei Nicotiana glutinosa gezählt. Die Tabakpflanze wurde täglich mit der Ferrisulfatlösung versorgt und nach 10 Tagen mit den Virus verimpft.

Tabelle VI.

\begin{tabular}{|c|c|c|c|c|}
\hline & Behandelt mit: & $\begin{array}{l}\text { Virus } \\
\text { allein }\end{array}$ & $\begin{array}{l}\text { Virus und } \\
\mathrm{n} / 250 \mathrm{Fe}_{2}\left(\mathrm{SO}_{4}\right)_{3}\end{array}$ & $\begin{array}{l}\text { Virus und } \\
\mathrm{n} / 500 \mathrm{Fe}_{2}\left(\mathrm{SO}_{4 / 3}\right.\end{array}$ \\
\hline Zahl der & Einzelherde...... & 55 & 38 & 42 \\
\hline
\end{tabular}

Die Durchschnittszahl der produzierten Einzelherde ist bei der mit Eisen behandelten Pflanze geringer, als bei der unbehandelten. Das verwandte Ferrisulfat wirkt also auf die Viruserkrankung hemmend. Die Versuche wurden weiter mit Nicotiana Tabacum angestellt. $\mathrm{n} / 100$ bis $\mathrm{n} / 1000$ Lösungen von Ferro- oder Ferrisulfat wurden jeden Tag den Tabakpflanzen gegeben und nach 1 Woche die Viruslösung beimpft. Um die Wirksamkeit der Eisenverbindungen zu ermitteln, wurden die Latenzzeit bis zum 
Auftreten der Krankheitssymptome sowje die Gesamtzahl der erkrankten Pflanzen bestimmt. Auch bei diesen Versuchen wurde die hemmende Wirkung des Eisens auf die Viruserkrankung festgestellt.

Die Arbeit wurde durch ein Stipendium des Unterrichtsministeriums gefördert.

(Aus dem Agrikulturchemischen Institut der Kyushu-Universitat in Fukuoka, Japan)

\section{LITERATUR}

1) Yamafuji u. Yuki, Biochem. Zs. 318, 107, 1947--2) Mörner, Nordiskt Med. Arch. Festband, 1, 1, 1896. 